\title{
Local control of bone metastases treated with external beam radiotherapy in recent years: a multicenter retrospective study
}

Kenji Makita ${ }^{1,2,3^{*}}$, Yasushi Hamamoto ${ }^{2}$, Hiromitsu Kanzaki², Masaaki Kataoka ${ }^{3}$, Shuhei Yamamoto ${ }^{3}$, Kei Nagasaki ${ }^{2}$, Hirofumi Ishikawa' ${ }^{1}$ Noriko Takata ${ }^{1}$, Shintaro Tsuruoka ${ }^{1}$, Kotaro Uwatsu $^{1}$ and Teruhito Kido ${ }^{1}$

\begin{abstract}
Background: Over the past decades, remarkable advancements in systemic drug therapy have improved the prognosis of patients with bone metastases. Individualization is required in external beam radiotherapy (EBRT) for bone metastases according to the patient's prognosis. To establish individualized EBRT for bone metastases, we investigated factors that affect the local control (LC) of bone metastases.

Methods: Between January 2010 and December 2019, 536 patients received EBRT for 751 predominantly osteolytic bone metastases. LC at EBRT sites was evaluated with a follow-up computed tomography. The median EBRT dose was biologically effective dose $\left(\mathrm{BED}_{10}\right.$ ) (39.0) (range of $\mathrm{BED}_{10}$ : 14.4-71.7 Gy).

Results: The median follow-up time and median time of computed tomography follow-up were 11 (range 1-123) months and 6 (range 1-119) months, respectively. The 0.5 - and 1-year overall survival rates were $73 \%$ and $54 \%$, respectively. The 0.5 - and 1 -year $L C$ rates were $83 \%$ and $79 \%$, respectively. In multivariate analysis, higher age ( $\geq 70$ years), non-vertebral bone metastases, unfavorable primary tumor sites (esophageal cancer, colorectal cancer, hepatobiliary/pancreatic cancer, renal/ureter cancer, sarcoma, melanoma, and mesothelioma), lower EBRT dose $\left(\mathrm{BED}_{10}<39.0 \mathrm{~Gy}\right)$, and non-administration of bone-modifying agents (BMAs)/antineoplastic agents after EBRT were significantly unfavorable factors for $L C$ of bone metastases. There was no statistically significant difference in the $L C$ between $\mathrm{BED}_{10}=39.0$ and $\mathrm{BED}_{10}>39.0 \mathrm{~Gy}$.

Conclusions: Regarding tumor-related factors, primary tumor sites and the sites of bone metastases were significant for the LC. As for treatment-related factors, lower EBRT doses (BED $10<39.0$ Gy) and non-administration of BMAs/antineoplastic agents after EBRT were associated with poor LC. Dose escalation from BED ${ }_{10}=39.0 \mathrm{~Gy}$ did not necessarily improve LC.
\end{abstract}

Keywords: Bone metastases, Local control, External beam radiotherapy, Prognostic factor, Individualized radiotherapy

\footnotetext{
*Correspondence: g447023u@mails.cc.ehime-u.ac.jp

${ }^{1}$ Department of Radiology, Ehime University Graduate School

of Medicine, 454 Shitsukawa, Toon, Ehime 791-0295, Japan

Full list of author information is available at the end of the article

The present study was presented in part at the ASTRO 62, Annual Congress of the American Society for Radiotherapy Oncology, Miami Beach, Florida (October 25-28, 2020).
}

\section{Background}

Various tumors frequently result in bone metastases, which are found in $70-85 \%$ of advanced cancers diagnosed at the time of death [1]. The incidence rate of bone metastases depends on the primary tumor site and is comparatively higher in breast, prostate, or lung cancers. Bone metastases contribute to only $<20 \%$ of the original author(s) and the source, provide a link to the Creative Commons licence, and indicate if changes were made. The images or other third party material in this article are included in the article's Creative Commons licence, unless indicated otherwise in a credit line to the material. If material is not included in the article's Creative Commons licence and your intended use is not permitted by statutory regulation or exceeds the permitted use, you will need to obtain permission directly from the copyright holder. To view a copy of this licence, visit http://creativecommons.org/licenses/by/4.0/. The Creative Commons Public Domain Dedication waiver (http://creativeco mmons.org/publicdomain/zero/1.0/) applies to the data made available in this article, unless otherwise stated in a credit line to the data. 
presenting symptoms at diagnosis [2], but can worsen the patient's quality of life (QOL) with progression.

Radiotherapy is useful for pain relief of bone metastases. In terms of pain relief and adverse events, singlefraction external beam radiotherapy (EBRT) of 8 Gy is comparable with 30 Gy in 10 fractions or 20 Gy in five fractions [3]. Many guidelines for managing of bone metastases recommend single-fraction EBRT of 8 Gy for pain relief of uncomplicated bone metastases. However, despite no significant difference in the duration of pain relief between single-fraction and fractionated EBRT, the period of pain relief tends to be longer after fractionated EBRT [4]. The incidence rate of retreatment was lower in fractionated EBRT than in single-fraction EBRT [5].

In recent years, the significant progress in systemic and supportive therapies has improved the expected prognosis of patients with advanced cancers [6, 7]. Thus, local control (LC) of bone metastases becomes more important for patients with a favorable prognosis. To individualize the EBRT for bone metastases, knowledge of factors associated with LC is essential; however, factors affecting LC of bone metastases (tumor-, treatment-, and patientrelated factors) have not been fully investigated. In this study, we aimed to determine the factors affecting the LC in bone metastases receiving EBRT.

\section{Methods}

Between January 2010 and December 2019, 1750 patients with 2345 bone metastatic lesions were treated with EBRT by three-dimensional conformal radiotherapy in three institutions: (a) cancer center $(\mathrm{n}=1514)$, (b) university hospital $(\mathrm{n}=594)$, and (c) community hospital $(n=237)$. It is often difficult to evaluate the tumor response to EBRT in predominantly osteoplastic bone metastases on computed tomography (CT) image because it was difficult to differentiate regrowth of predominantly osteoplastic bone metastases from reparative ossification after radiotherapy. Therefore, only predominantly osteolytic bone metastases were examined. A total of 536 patients with 751 predominantly osteolytic bone metastatic lesions were followed up with $\mathrm{CT} \geq 2$ months (including regrowth in $<2$ months) after EBRT treatment. The LC of EBRT sites in these patients was evaluated in this retrospective analysis (Fig. 1).

\section{Radiotherapy}

The doses of EBRT were determined at the discretion of each physicist and institution; 30 Gy in 10 fractions was the most frequently used dosage. EBRT was performed with 6- to 10-MV X-ray of linear accelerators, and the doses of the target volumes were prescribed to be $\geq 90 \%$ of the EBRT dose, in principle. The biologically effective dose (BED) was calculated to compare the various

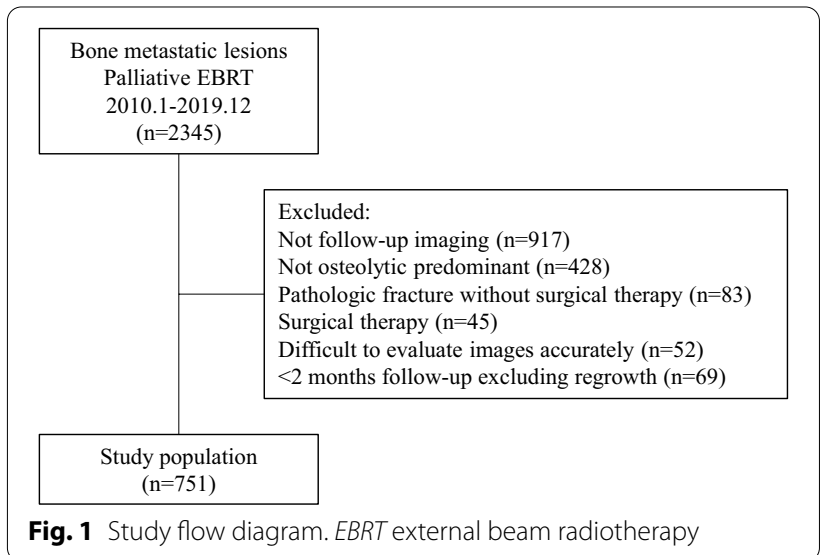

fractionated schedules. The $\mathrm{BED}_{10}$ (BED calculated using an $\alpha / \beta$ of $10 \mathrm{~Gy})$ was calculated by $n d(1+d /(\alpha / \beta))$, where $d$ is the fraction dose, $n$ is the number of fractions, and $\alpha / \beta$ is $10 \mathrm{~Gy}$.

\section{Effectiveness assessment}

The primary endpoint of this study was the LC of EBRT sites for bone metastases. The extracted outcomes were classified according to the presence or absence of local recurrence, or local regrowth, at the EBRT sites of bone metastases. Local control was defined as when the irradiated bone metastases were stable or shrunk. Two observers (a radiologist and a radiation oncologist) were blinded to the follow-up information and outcomes during the evaluation of the images.

\section{Statistical analyses}

The survival duration and the LC period of EBRT sites were calculated from the start of palliative EBRT. The Kaplan-Meier method was used to generate LC and overall survival (OS) curves. We assessed the predictive factors associated with LC rates of EBRT sites using univariate and multivariate Cox proportional hazards models to determine hazard ratios (HRs), including 95\% confidence intervals (CIs) and p-value. Variables included in the multivariate models had a p-value of $<0.1$ in the univariate analysis. Statistical analyses were performed using the JMP software (JMP version 14.3.0; SAS Institute, Cary, NC, USA).

\section{Results}

Data from 536 patients (male/female $=315 / 221$; age, median [range]: 66 [12-90] years) with 751 lesions were included in the analysis dataset. The median follow-up time and median time of CT follow-up were 11 (range: 1-123) months and 6 (range: 1-119) months, respectively. Details of the lesion characteristics are shown in 
Table 1. The median EBRT dose was $\mathrm{BED}_{10}=39.0$ Gy (=30 Gy in 10 fractions). The other fraction schedules, in sequential order, for EBRT of $\mathrm{BED}_{10}$ (=fraction schedules) were as follows: $14.4 \mathrm{~Gy}(=1 \times 8 \mathrm{~Gy})$, 28.0 Gy $(=5 \times 4$ Gy), 30.0 Gy $(=4 \times 5$ Gy), 31.2 Gy $(=10 \times 2.5$ Gy $), \quad 46.9-56.2$ Gy $(=15-18 \times 2.5$ Gy $)$,

Table 1 Characteristics of lesions

\begin{tabular}{|c|c|c|}
\hline Characteristic & No. of lesions & $\%$ \\
\hline \multicolumn{3}{|l|}{ Age } \\
\hline$<70$ years & 504 & 67.1 \\
\hline$\geq 70$ years & 247 & 32.9 \\
\hline \multicolumn{3}{|l|}{ Sex } \\
\hline Male & 447 & 59.5 \\
\hline Female & 304 & 49.5 \\
\hline \multicolumn{3}{|l|}{ Primary tumor sites } \\
\hline Lung & 248 & 33.0 \\
\hline Breast & 137 & 18.2 \\
\hline Head and neck & 53 & 7.1 \\
\hline Esophagus & 15 & 2.0 \\
\hline Hepatobiliary/pancreatic & 95 & 12.7 \\
\hline Kidney/ureter & 74 & 9.9 \\
\hline Colorectal & 31 & 4.1 \\
\hline Gynecological & 19 & 2.5 \\
\hline Sarcoma/melanoma/mesothelioma & 18 & 2.4 \\
\hline Others & 61 & 8.1 \\
\hline \multicolumn{3}{|l|}{ EBRT sites } \\
\hline Vertebral & 445 & 59.2 \\
\hline Pelvis & 182 & 24.2 \\
\hline Rib & 65 & 8.7 \\
\hline Others & 59 & 7.9 \\
\hline \multicolumn{3}{|l|}{ Bone cortex destruction } \\
\hline Yes & 557 & 74.2 \\
\hline No & 194 & 25.8 \\
\hline \multicolumn{3}{|l|}{ EBRT dose $\left(B E D_{10}\right)$} \\
\hline \multicolumn{3}{|l|}{ Median: 39.0 (14.4-71.7) } \\
\hline 14.4 & 22 & 2.9 \\
\hline$>14.4,<39.0$ & 84 & 11.2 \\
\hline 39 & 434 & 57.8 \\
\hline$>39.0$ & 211 & 28.1 \\
\hline \multicolumn{3}{|l|}{ Post-EBRT BMAs } \\
\hline Yes & 460 & 61.3 \\
\hline No & 291 & 38.7 \\
\hline \multicolumn{3}{|l|}{ Pre-EBRT ATS } \\
\hline Yes & 408 & 54.3 \\
\hline No & 343 & 45.7 \\
\hline \multicolumn{3}{|l|}{ Post-EBRT ATs } \\
\hline Yes & 518 & 69.0 \\
\hline No & 233 & 31.0 \\
\hline
\end{tabular}

EBRT External beam radiotherapy, BMAs bone modifying agents, $A T$ s antineoplastic agents, $B E D$ biologically effective dose
42.9-58.8 Gy $(=11-15 \times 3 \quad$ Gy $), \quad 50.4-60.0$ Gy $(=21-25 \times 2$ Gy $), 39.7$ Gy $(=5 \times 4 \quad$ Gy $+3 \times 3$ Gy $)$, 47.2 Gy $(=5 \times 4$ Gy $+8 \times 2$ Gy $)$ and 71.7 Gy $(=3 \times 3 \mathrm{~Gy}+25 \times 2 \mathrm{~Gy})$.

\section{Overall survival (OS) and local control (LC) of the external beam radiotherapy (EBRT) sites}

The 0.5 - and 1-year OS rates were $73 \%$ and $54 \%$, respectively (Fig. 2). The 1-year OS rates from January 2010 to December 2016 and from January 2017 to December 2019 were $52 \%$ and $58 \%$, respectively $(\mathrm{p}=0.026$, log-rank).

Local recurrence was observed in $19.6 \%(147 / 751)$ of EBRT sites, and the median time to recurrence was 3 (range: 1-106) months. The 0.5- and 1-year LC rates of EBRT sites were $83 \%$ and $79 \%$, respectively (Fig. 3a). The OS rate of patients with local regrowth and those without local regrowth was $60 \%$ and $76 \%$, respectively at 0.5 -year, and $38 \%$ and $58 \%$, respectively at 1 -year $(\mathrm{p}=0.001$, logrank). In addition, the 0.5 - and 1-year OS rates after the local regrowth were $33 \%$ and $19 \%$, respectively.

\section{LC according to primary tumor sites}

Our study's primary tumor sites were classified into three groups based on reported radiosensitivity [8] and 1-year LC rates (Table 2). Esophageal cancer, colorectal cancer, and hepatobiliary/pancreatic cancer were classified as the unfavorable group. Kidney/ureter cancer and nonepithelial tumors (sarcoma/melanoma/mesothelioma) were classified as the moderately unfavorable group. The remaining (i.e., lung cancer, breast cancer, head and neck cancer, gastric cancer, genitourinary cancer, and skin cancers) were classified as the favorable group.

The 0.5- and 1-year LC rates were $62 \%$ and $47 \%$ for the unfavorable, $77 \%$ and $77 \%$ for the moderately unfavorable, and $89 \%$ and $87 \%$ for the favorable groups,

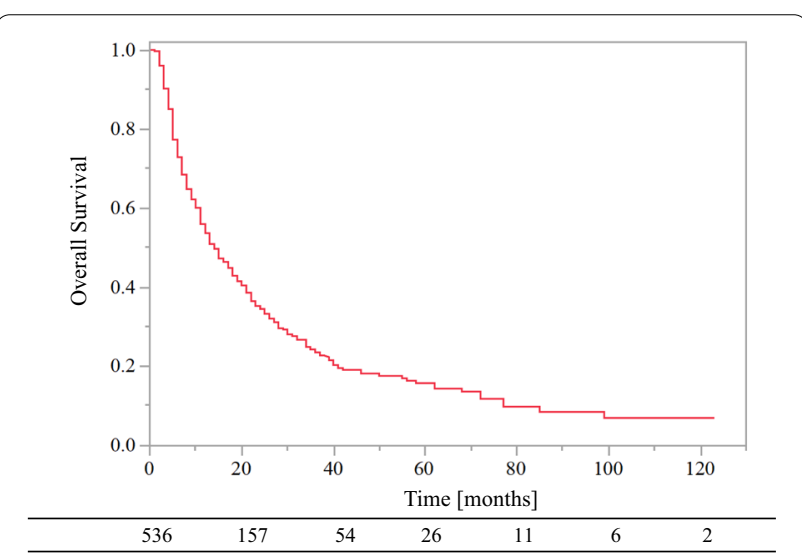

Fig. 2 Overall survival of all patients 
a) Local control of all bone metastatic bone lesions

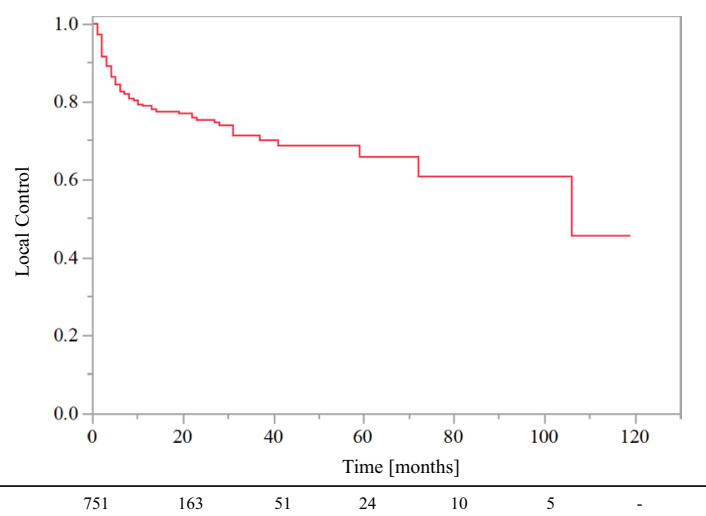

c) EBRT sites (vertebral bone vs. other bone)

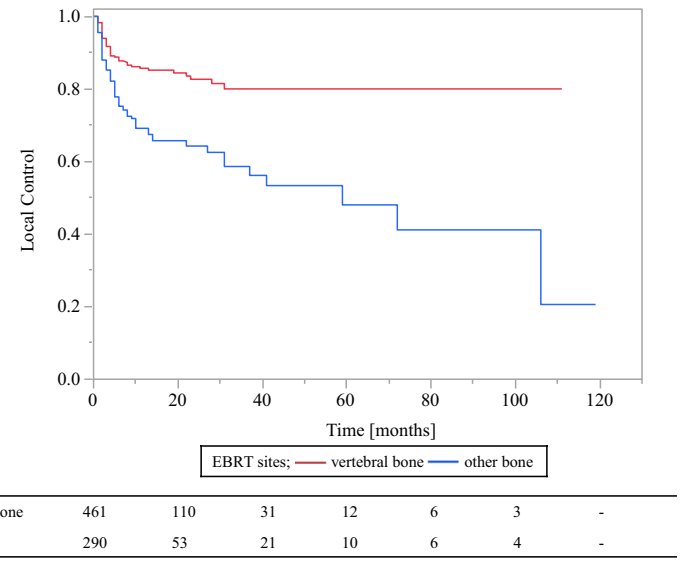

b) Primary tumor sites

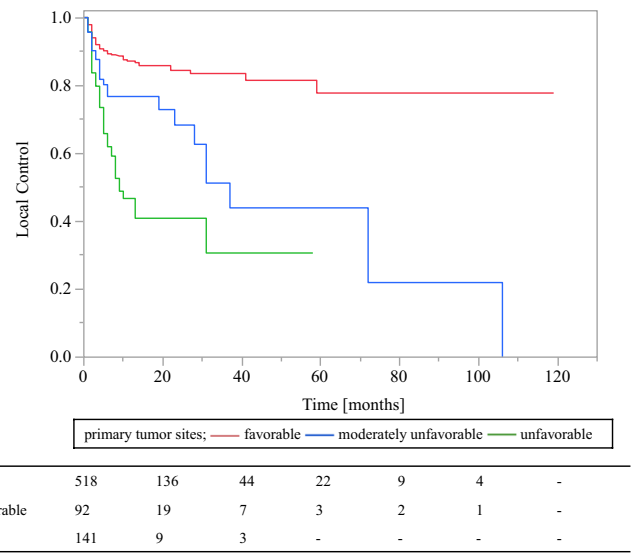

d) EBRT dose $\left(\mathrm{BED}_{10}\right)$

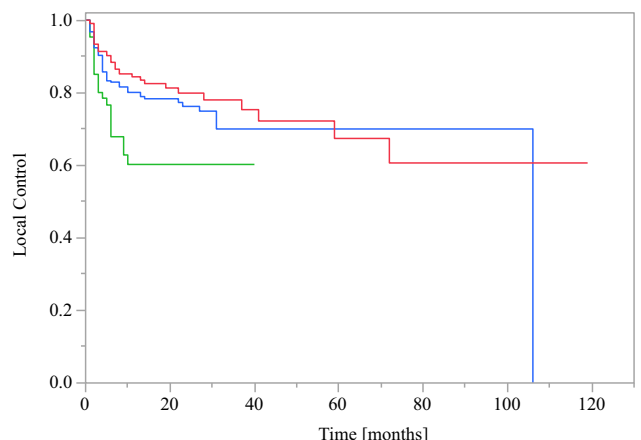

EBRT dose $\left(\mathrm{BED}_{10}\right) ;->39 \mathrm{~Gy}-=39 \mathrm{~Gy}-<39 \mathrm{~Gy}$

\begin{tabular}{llllllll}
\hline$>39$ Gy & 211 & 67 & 25 & 15 & 9 & 4 & - \\
$=39$ Gy & 433 & 85 & 25 & 9 & 3 & 2 & - \\
$<39$ Gy & 107 & 13 & 2 & - & - & - & - \\
\hline
\end{tabular}

Fig. 3 Local control of bone metastases. a Local control of all bone metastatic bone lesions. b Primary tumor sites (favorable group vs. moderately unfavorable group vs. unfavorable group; favorable group: head and neck, lung/mediastinal, breast, gastric, gynecologic, prostate, bladder, and skin cancers; moderately unfavorable group: kidney/ureter and non-epithelial cancers; unfavorable group: esophageal, colorectal, and hepatobiliary/ pancreatic cancers). c EBRT sites (vertebral bone vs. other bone). d EBRT dose (BED 10$)$ (<39.0 Gy vs. 39.0 Gy vs. > 39.0 Gy). BED Biologically effective dose, EBRT external beam radiotherapy

respectively (Fig. 3b). On univariate analysis, LC rates were significantly lower in the unfavorable group compared with the moderately unfavorable group (HR 1.84, 95\% CI 1.15-2.95, $\mathrm{p}=0.011$ [Table 3]) and significantly higher in the favorable group compared with the moderately unfavorable group (HR 0.40, 95\% CI 0.26-0.64, $\mathrm{p}<0.001$ [Table 3]).

\section{LC according to EBRT sites}

The 0.5- and 1-year LC rates after EBRT were 88\% and $86 \%$ for vertebral metastases and $75 \%$ and $69 \%$ for non-vertebral bone metastases (Fig. 3c). On univariate analysis, the LC rates were significantly lower in the nonvertebral bone metastases compared with the vertebral bone metastases (HR 2.34, 95\% CI 1.69-3.25, $\mathrm{p}<0.001$ [Table 3]).

\section{LC according to EBRT doses $\left(\right.$ BED $\left._{10}\right)$}

The 0.5- and 1-year LC rates were $68 \%$ and $60 \%$ for $\mathrm{BED}_{10}<39.0 \mathrm{~Gy}, 83 \%$ and $80 \%$ for $\mathrm{BED}_{10}=39.0 \mathrm{~Gy}$, and $88 \%$ and $84 \%$ for $\mathrm{BED}_{10}>39.0$ Gy (Fig. 3d). The LC rate was significantly lower for $\mathrm{BED}_{10}<39.0$ Gy than $\mathrm{BED}_{10} \geq 39.0$ Gy (HR 2.02, 95\% CI 1.34-3.05, $\left.\mathrm{p}=0.001\right)$ on univariate analysis. In addition, there were statistically significant differences in LC rates between $\mathrm{BED}_{10}<39.0 \mathrm{~Gy}$ and $\mathrm{BED}_{10}=39.0$ Gy (HR 1.87, 95\% CI $1.22-2.87, \mathrm{p}=0.004)$. In contrast, no statistically significant differences were found between $\mathrm{BED}_{10}=39.0 \mathrm{~Gy}$ 
Table 2 Risk group classification of primary tumor sites according to local control rates

\begin{tabular}{|c|c|c|c|}
\hline Primary tumor sites & 6 months (\%) & 12 months (\%) & $\begin{array}{l}36 \text { months } \\
(\%)\end{array}$ \\
\hline \multicolumn{4}{|l|}{ Unfavorable group } \\
\hline Esophagus & 61 & 49 & 49 \\
\hline Hepatobiliary/pancreatic & 54 & 49 & 38 \\
\hline colorectal & 85 & 43 & 21 \\
\hline \multicolumn{4}{|l|}{ Moderately unfavorable group } \\
\hline Kidney/ureter & 75 & 75 & 48 \\
\hline Sarcoma/melanoma/mesothelioma & 84 & 84 & 28 \\
\hline \multicolumn{4}{|l|}{ Favorable group } \\
\hline Lung & 83 & 79 & 76 \\
\hline Breast & 98 & 98 & 98 \\
\hline Head and neck & 88 & 88 & 68 \\
\hline Gynecological & 100 & 100 & 86 \\
\hline Others & 94 & 86 & 86 \\
\hline
\end{tabular}

Table 3 Local control rates after EBRT and results of univariate and multivariate analyses

\begin{tabular}{|c|c|c|c|c|c|c|c|}
\hline & & \multirow[t]{2}{*}{0.5 -year (\%) } & \multirow[t]{2}{*}{1 -year (\%) } & \multicolumn{2}{|c|}{ Univariate analysis } & \multicolumn{2}{|c|}{ Multivariate analysis } \\
\hline & & & & $\mathrm{HR}(95 \% \mathrm{Cl})$ & $P$ & $\mathrm{HR}(95 \% \mathrm{Cl})$ & $P$ \\
\hline Age & $<70$ years $v s . \geq 70$ years & 89 vs. 71 & 84 vs. 69 & $2.32(1.68-3.21)$ & $<0.001$ & $2.34(1.62-3.40)$ & $<0.001$ \\
\hline Sex & Female vs. male & 88 vs. 78 & 86 vs. 73 & $1.92(1.35-2.72)$ & $<0.001$ & $1.15(0.76-1.73)$ & 0.514 \\
\hline \multirow[t]{2}{*}{ Primary tumor sites } & Moderately unfavorable vs. favorable & 77 vs. 89 & 77 vs. 87 & $0.40(0.26-0.64)$ & $<0.001$ & $0.49(0.29-0.81)$ & 0.006 \\
\hline & Moderately unfavorable vs. unfavorable & 77 vs. 62 & 77 vs. 47 & $1.84(1.15-2.95)$ & 0.011 & $2.28(1.34-3.86)$ & 0.002 \\
\hline EBRT sites & Vertebral bone vs. other bone & 88 vs. 75 & 86 vs. 69 & $2.34(1.69-3.25)$ & $<0.001$ & $1.78(1.24-2.57)$ & 0.002 \\
\hline EBRT dose $\left(\right.$ BED $\left._{10}\right)$ & $\geq 39.0$ Gy vs.<39.0 Gy & 85 vs. 68 & 82 vs. 60 & $2.02(1.34-3.05)$ & 0.001 & $2.08(1.31-3.30)$ & 0.002 \\
\hline Post-EBRT BMAs & Yes vs. no & 88 vs. 74 & 86 vs. 67 & $2.49(1.79-3.46)$ & $<0.001$ & $1.94(1.34-2.83)$ & $<0.001$ \\
\hline Post-EBRT ATs & Yes vs. no & 88 vs. 70 & 84 vs. 65 & $2.41(1.73-3.36)$ & $<0.001$ & $1.58(1.08-2.31)$ & 0.018 \\
\hline Bone cortex destruction & Yes vs. no & 80 vs. 90 & 77 vs. 84 & $0.70(0.46-1.05)$ & 0.083 & $0.67(0.42-1.06)$ & 0.084 \\
\hline Pre-EBRT ATs & Yes vs. no & 85 vs. 80 & 80 vs. 78 & $1.24(0.89-1.71)$ & 0.198 & - & - \\
\hline
\end{tabular}

EBRT External beam radiotherapy, BMAs bone modifying agents, $A T s$ antineoplastic agents, $B E D$ biologically effective dose

and $\mathrm{BED}_{10}>39.0$ Gy $(\mathrm{HR}$ 1.26, 95\% CI $0.86-1.87$, $\mathrm{p}=0.240)$.

\section{Dose escalation from $\mathrm{BED}_{10}=39.0 \mathrm{~Gy}$ and $\mathrm{LC}$ according to primary tumor sites and metastatic sites According to primary tumor sites}

For the unfavorable group of primary tumor sites, the 1 -year $\mathrm{LC}$ rates of $\mathrm{BED}_{10}=39.0$ and $\mathrm{BED}_{10}>39.0$ Gy were $46 \%$ and $59 \%$, respectively (HR 1.44, 95\% CI 0.77-2.70, $\mathrm{p}=0.251$ ). For the moderately unfavorable group of primary tumor sites, the 1 -year $\mathrm{LC}$ rates of $\mathrm{BED}_{10}=39.0$ and $\mathrm{BED}_{10}>39.0$ Gy were $78 \%$ and $86 \%$, respectively (HR 1.75 , $95 \%$ CI $0.70-4.36, \mathrm{p}=0.232$ ). For the favorable group of primary tumor sites, the 1-year $\mathrm{LC}$ rates of $\mathrm{BED}_{10}=39.0$ and $\mathrm{BED}_{10}>39.0$ Gy were $90 \%$ and $94 \%$, respectively (HR $1.16,95 \%$ CI $0.63-2.13, \mathrm{p}=0.631$ ). Dose escalation from
$\mathrm{BED}_{10}=39.0$ Gy did not improve LC significantly, especially for the favorable group.

\section{According to metastatic sites}

For vertebral metastases, the 1-year LC rates were $86 \%$ and $91 \%$ for $\mathrm{BED}_{10}=39.0$ and $\mathrm{BED}_{10}>39.0 \mathrm{~Gy}$, respectively (HR $1.17,95 \%$ CI $0.64-2.16, p=0.615$ ). For nonvertebral bone metastases, the 1-year LC rates were $69 \%$ and $80 \%$ for $\mathrm{BED}_{10}=39.0$ and $\mathrm{BED}_{10}>39.0 \mathrm{~Gy}$, respectively (HR 1.59, 95\% CI 0.96-2.62, p=0.070). Dose escalation from $\mathrm{BED}_{10}=39.0$ Gy tended to improve $\mathrm{LC}$ for non-vertebral bone metastases.

The incidence of high dose $\operatorname{EBRT}\left(\mathrm{BED}_{10} \geq 39.0 \mathrm{~Gy}\right)$ was not different according to metastatic sites (vertebral bone, 86.6\%; non-vertebral bone, $85.3 \%$; $p=0.619$, chisquare test). The proportion of bone metastases from the 
unfavorable and moderately unfavorable primary tumor sites was higher in non-vertebral bone compared to vertebral bone metastases $(39.0 \%$ vs. $26.0 \%, \mathrm{p}<0.001$, chisquare test).

\section{LC according to other factors}

Male, higher age ( $\geq 70$ years), non-administration of BMAs/antineoplastic agents (ATs, including hormone therapy) after EBRT (post-EBRT BMAs/ATs), and the destruction of cortical bone were statistically significant unfavorable factors for LC on univariate analysis (Table 3). In principle, cytotoxic chemotherapy, biotherapy, and immune-checkpoint inhibitor were not used in concurrent combination therapy with EBRT. The administration of ATs before EBRT (pre-EBRT ATs) was not a significant factor for LC on the univariate analysis (Table 3).

\section{Multivariate Cox regression analysis}

On multivariate analysis, higher age ( $\geq 70$ years), bone metastases from unfavorable/moderately unfavorable groups of primary tumor sites, non-vertebral bone metastases, EBRT dose of $\mathrm{BED}_{10}<39.0 \mathrm{~Gy}$, and nonadministration of BMAs/ATs after EBRT were significantly unfavorable independent factors for LC (Table 3).

\section{Discussion}

Among the patients who received EBRT to bone metastases in recent years, approximately half of them were estimated to survive for 1 year. Approximately $80 \%$ of the bone metastases receiving EBRT in clinical practice were estimated to achieve LC for 1 year in our practice. LC rates after EBRT were satisfactory for the majority of patients. LC rates were influenced by some tumor-, treatment-, and patient-related factors. Regarding tumorrelated factors, both primary tumor sites and sites of bone metastases (vertebral bone vs. non-vertebral bone) were associated with LC. Regarding treatment-related factors, lower doses of EBRT $\left(\mathrm{BED}_{10}<39.0 \mathrm{~Gy}\right)$ and nonadministration of BMAs/ATs after EBRT were associated with poor LC. Interestingly, dose escalation from a $\mathrm{BED}_{10}=39.0$ Gy did not necessarily lead to improvement of LC. Regarding patient-related factors, higher age ( $\geq 70$ years) seemed to be associated with poor LC.

Recently, long-term LC of bone metastases is required for patients with relatively good prognosis. In contrast, some patients still have a poor prognosis despite advancements in systemic therapy. Katagiri reported that the 3-year OS rate of patients with bone metastases was $23 \%$ [9], which is similar to that in our study (24\%). It is noteworthy that one-fifth of the patients with bone metastases were estimated to survive 3 years or more.
These patients may need more aggressive EBRT for bone metastases.

For bone metastases from unfavorable and moderately unfavorable primary tumor sites, approximately half progressed within 1-3 years after EBRT. In addition, the prognosis of patients with unfavorable and moderately unfavorable primary tumor sites was generally poorer. The 1-year OS rate of these patients was only $41 \%$ (data not shown) in our present study. Therefore, the majority of patients with unfavorable and moderately unfavorable primary tumor sites may not experience a decrease in QOL due to bone metastases. However, some patients with unfavorable and moderately unfavorable primary tumor sites survive for a relatively long time and experience a decrease in QOL. Considering the poor LC rates of bone metastases from unfavorable and moderately unfavorable primary tumor sites, EBRT with a median $\mathrm{BED}_{10}=39.0$ Gy seemed to be insufficient for some longterm survivors who have unfavorable and moderately unfavorable primary tumor sites. More aggressive EBRT, such as stereotactic body radiotherapy (SBRT) or heavy ion therapy, may be better performed for these patients. Some studies have shown that SBRT for bone metastases from renal cell cancer, sarcoma, and melanoma (which were included in the moderately unfavorable group of primary tumor sites) achieved good LC of the irradiated sites [10-12]. However, bone metastases from hepatocellular carcinoma and colorectal cancer (which were included in the unfavorable group of primary tumor sites) were difficult to control, regardless of using SBRT $[13,14]$. Although further studies are needed, it may be difficult to control bone metastases from unfavorable primary tumor sites. LC rates of bone metastases from favorable primary tumor sites were generally satisfactory, with a 1-year LC rate of approximately 90\%. Although stereotactic radiosurgery seems to further increase LC [15], conventional EBRT seems to be suitable for the majority of patients with favorable primary tumor sites.

The site of bone metastases was associated with the LC in our study. LC rates of vertebral metastases were higher compared with those of other bone metastases. The EBRT site of bone metastases is considered to occur through a multistep process involving interactions between cancer cells and normal host cells [16]. Vertebral metastases often occur via Batson's vertebral venous plexus, which bypasses the lung and liver [17]. Because of the lack of checkpoints such as the lung and liver, cancer cells in vertebral metastases may have slightly different characteristics from those in non-vertebral bone metastases. It remains unclear why LC of vertebral metastases was better, but this could be one of the possible explanations for the difference in radiosensitivity between vertebral metastases and non-vertebral bone metastases. 
It was true that the proportion of bone metastases from favorable primary tumor sites were higher in vertebral metastases compared to non-vertebral metastases; multivariate analysis showed vertebral metastases were independently significant favorable factors for local control. Therefore, we think that vertebral metastases were favorable factors for local control.

Regarding treatment-related factors, $\mathrm{BED}_{10}<39.0$ Gy and non-administration of BMAs/ATs after EBRT were unfavorable factors for LC of bone metastases in our present study. Although it has been reported that LC of bone metastases tends to be dose dependent [18-21], there was no significant difference in LC rates between $\mathrm{BED}_{10}=39.0 \mathrm{~Gy}$ and $\mathrm{BED}_{10}>39.0 \mathrm{~Gy}$. Especially for bone metastases from favorable primary tumor sites, dose escalation from $\mathrm{BED}_{10}=39.0$ Gy seemed to have little effect on LC rates (39.0 Gy, 90\% at 1 year; $>39.0 \mathrm{~Gy}$, $94 \%$ at 1 year). In contrast, dose escalation from $\mathrm{BED}_{10}=39.0 \mathrm{~Gy}$ tended to improve $\mathrm{LC}$ in non-vertebral bone metastases $(39.0 \mathrm{~Gy}, 69 \%$ at 1 year; $>39.0 \mathrm{~Gy}, 80 \%$ at 1 year). Further studies are needed to identify the bone metastases that will benefit from more aggressive EBRT.

Another treatment-related factor for LC of bone metastases was the administration of systemic drug therapy after EBRT. Non-administration of BMAs/ATs after EBRT was an unfavorable factor for LC of bone metastases. Several studies have shown that a combination of EBRT and BMAs improved effectiveness compared with EBRT alone or BMAs alone [22-24]. The response rate of bone metastases to ATs was 8-59\% [25-34]. BMAs and ATs after EBRT seemed to potentially enhance the effect of EBRT on bone metastases. Administration of BMAs and ATs after EBRT seemed to be useful in patients with good prognosis.

This study has some limitations owing to its retrospective nature. First, osteoplastic bone metastases were excluded from this study because it is often difficult to evaluate the LC. As a result, many bone metastases from prostate cancer, which are often osteoplastic, were excluded from our present study. Second, the number of each primary tumor site was relatively small; hence, there is a possibility that the LC according to the primary tumor site was not evaluated accurately. There remained the possibility that dose escalation in EBRT from $\mathrm{BED}_{10}>39.0$ Gy may be beneficial for bone metastases with a comparatively good prognosis and radio-resistant nature. For example, EBRT of $>50 \mathrm{~Gy}$ improved LC compared with EBRT of $<50$ Gy in bone metastases from differentiated thyroid cancer [19]. Third, there might be a selection bias in the determination of EBRT doses because many attending radiation oncologists were involved in the management of patients due to the multicenter and long-term study design. Finally, detailed information on pain was unavailable from the clinical records of many patients. Therefore, the relationship between regrowth of bone metastases and pain could not be evaluated. Although patients with poor prognoses need only short-term pain control, patients with good prognoses are likely to need long-term local control of EBRT sites. Knowledge of factors that affects LC of bone metastases is essential for long-term local control. We believe that knowledge of factors affecting LC of bone metastases is the basis of individualized radiotherapy.

Tumor-, treatment-, and patient-related factors influenced the LC of bone metastases after EBRT. For tumor-related factors, not only primary tumor sites but also sites of bone metastases are significant for the LC. After conventional EBRT with the median dose of $\mathrm{BED}_{10}=39.0 \mathrm{~Gy}, \mathrm{LC}$ rates of bone metastases were favorable for many cancers, whereas they were lower for esophageal cancer, colorectal cancer, hepatobiliary/ pancreatic cancer, kidney/ureter cancer, and sarcoma/ melanoma/mesothelioma. Vertebral metastases showed significantly better LC compared with metastases of other bones. As for treatment-related factors, lower EBRT doses $\left(\mathrm{BED}_{10}<39.0 \mathrm{~Gy}\right)$ and non-administration of BMAs/ATs were associated with poor LC. Dose escalation in EBRT from a $\mathrm{BED}_{10}=39.0$ Gy did not necessarily improve LC. In addition to the predicted prognosis, these results should be considered for the individualization of EBRT for bone metastases.

\section{Abbreviations \\ ATs: Antineoplastic agents; $\mathrm{BED}_{10}$ : Biologically effective dose; BMAs: Bone- modifying agents; Cls: Confidence intervals; CT: Computed tomography; EBRT: External beam radiotherapy; HRs: Hazard ratios; LC: Local control; OS: Overall survival; QOL: Quality of life.}

\section{Acknowledgements}

We would like to thank Editage (www.editage.jp) for English language editing.

\section{Authors' contributions}

$\mathrm{KM}$ and $\mathrm{YH}$ designed the study concepts. KM, HK, SY, KN, IH, NT, and ST collected patient data and drafted the article. KM, HK, YH, MK, KN, IH, NT, ST, KU, and TK collaborated in the discussion. KM and $\mathrm{YH}$ prepared the manuscript and MK and HK edited the manuscript. All authors read and approved the final manuscript

\section{Funding}

Not applicable.

Availability of data and materials Not applicable.

\section{Declarations}

Ethics approval and consent to participate

All procedures performed in studies involving human participants were in accordance with the ethical standards of the institutional research committee and with the 1964 Declaration of Helsinki and its later amendments or comparable ethical standards. 


\section{Consent for publication}

Patients treated at Shikoku Cancer Center, Ehime University Hospital, and Saiseikai Imabari Hospital consented in writing for the use of their anonymous data for research.

\section{Competing interests}

The authors declare that they have no competing interests.

\section{Author details}

${ }^{1}$ Department of Radiology, Ehime University Graduate School of Medicine, 454 Shitsukawa, Toon, Ehime 791-0295, Japan. ${ }^{2}$ Department of Radiation Oncology, National Hospital Organization Shikoku Cancer Center, Kou-160, Minami-Umenomoto-Machi, Matsuyama, Ehime 791-0280, Japan. ${ }^{3}$ Department of Radiology, Saiseikai Imabari Hospital, 7-1-6 Kita-machi, Imabari, Ehime 799-1592, Japan.

\section{Received: 25 August 2021 Accepted: 27 October 2021}

Published online: 20 November 2021

\section{References}

1. Tubiana-Hulin M. Incidence, prevalence and distribution of bone metastases. Bone. 1991;1:S9-10.

2. De Felice F, Piccioli A, Musio D, Tombolini V. The role of radiation therapy in bone metastases management. Oncotarget. 2017;8:25691-9.

3. Chow E, Zeng L, Salvo N, Dennis K, Tsao M, Lutz S. Update on the systematic review of palliative radiotherapy trials for bone metastases. Clin Oncol ( $R$ Coll Radiol). 2012;24:112-4.

4. Steenland E, Leer JW, van Houwelingen H, Post WJ, van den Hout WB, Kievit $J$, et al. The effect of a single fraction compared to multiple fractions on painful bone metastases: a global analysis of the Dutch Bone Metastasis Study. Radiother Oncol. 1999;52:101-9.

5. Rich SE, Chow R, Raman S, Liang Zeng K, Lutz S, Lam H, et al. Update of the systematic review of palliative radiation therapy fractionation for bone metastases. Radiother Oncol. 2018;126:547-57.

6. André T, Shiu KK, Kim TW, Jensen BV, Jensen LH, Punt C, et al. Pembrolizumab in microsatellite-instability-high advanced colorectal cancer. N Engl J Med. 2020;383:2207-18

7. Antonia SJ, Villegas A, Daniel D, Vicente D, Murakami S, Hui R, et al. Overall survival with durvalumab after chemoradiotherapy in stage III NSCLC. N Engl J Med. 2018;379:2342-50.

8. Gerszten PC, Mendel E, Yamada Y. Radiotherapy and radiosurgery for metastatic spine disease: what are the options, indications, and outcomes? Spine. 2009;34:S78-92.

9. Katagiri H, Okada R, Takagi T, Takahashi M, Murata H, Harada H, et al. New prognostic factors and scoring system for patients with skeletal metastasis. Cancer Med. 2014;3:1359-67.

10. Smith BW, Joseph JR, Saadeh YS, La Marca F, Szerlip NJ, Schermerhorn TC, et al. Radiosurgery for treatment of renal cell metastases to spine: a systematic review of the literature. World Neurosurg. 2018;109:e502-9.

11. Leeman JE, Bilsky M, Laufer I, Folkert MR, Taunk NK, Osborne JR, et al. Stereotactic body radiotherapy for metastatic spinal sarcoma: a detailed patterns-of-failure study. J Neurosurg Spine. 2016;25:52-8.

12. Stinauer MA, Kavanagh BD, Schefter TE, Gonzalez R, Flaig T, Lewis K, et al. Stereotactic body radiation therapy for melanoma and renal cell carcinoma: impact of single fraction equivalent dose on local control. Radiat Oncol. 2011;6:34.

13. Ito K, Ogawa H, Shimizuguchi T, Nihei K, Furuya T, Tanaka H, et al. Stereotactic body radiotherapy for spinal metastases: clinical experience in 134 cases from a single Japanese institution. Technol Cancer Res Treat. 2018;17:1533033818806472.

14. McGee HM, Carpenter TJ, Ozbek U, Kirkwood KA, Tseng TC, Blacksburg S, et al. Analysis of local control and pain control after spine stereotactic radiosurgery reveals inferior outcomes for hepatocellular carcinoma compared with other radioresistant histologies. Pract Radiat Oncol. 2019;9:89-97.

15. Singh R, Lehrer EJ, Dahshan B, Palmer JD, Sahgal A, Gerszten PC, et al. Single fraction radiosurgery, fractionated radiosurgery, and conventional radiotherapy for spinal oligometastasis (SAFFRON): a systematic review and meta-analysis. Radiother Oncol. 2020;146:76-89.
16. Paget $\mathrm{S}$. The distribution of secondary growths in cancer of the breast. Lancet. 1889;133:571-3.

17. Batson OV. The vertebral vein system as mechanism for spread of metastases. Am J Roentgenol Radium Ther Nucl Med. 1942;48:715-8.

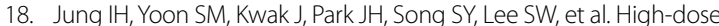
radiotherapy is associated with better local control of bone metastasis from hepatocellular carcinoma. Oncotarget. 2017:8:15182-92.

19. Makita K, Hamamoto Y, Tsuruoka S, Takata N, Urashima Y, Miyagawa M, et al. Treatment intensity and control rates in combining external-beam radiotherapy and radioactive iodine therapy for metastatic or recurrent differentiated thyroid cancer. Int J Clin Oncol. 2020;25:691-7.

20. Rades D, Fehlauer F, Schulte R, Veninga T, Stalpers L, Basic H, et al. Prognostic factors for local control and survival after radiotherapy of metastatic spinal cord compression. J Clin Oncol. 2006;24:3388-93.

21. Rades D, Cacicedo J, Conde-Moreno AJ, Segedin B, But-Hadzic J, Groselj $B$, et al. Precision radiation therapy for metastatic spinal cord compression: final results of the PRE-MODE trial. Int J Radiat Oncol Biol Phys. 2020;106:780-9.

22. Rades D, Hakim SG, Bajrovic A, Karstens JH, Veninga T, Rudat V, et al. Impact of zoledronic acid on control of metastatic spinal cord compression. Strahlenther Onkol. 2012;188:910-6.

23. Vassiliou V, Kalogeropoulou C, Christopoulos C, Solomou E, Leotsinides M, Kardamakis D. Combination ibandronate and radiotherapy for the treatment of bone metastases: clinical evaluation and radiologic assessment. Int J Radiat Oncol Biol Phys. 2007;67:264-72.

24. Tanaka H, Makita C, Manabe Y, Kajima M, Matsuyama K, Matsuo M. Radiation therapy combined with bone-modifying agents ameliorates local control of osteolytic bone metastases in breast cancer. J Radiat Res. 2020;61:494-8.

25. Scheid V, Buzdar AU, Smith TL, Hortobagyi GN. Clinical course of breast cancer patients with osseous metastasis treated with combination chemotherapy. Cancer. 1986;58:2589-93.

26. Hortobagyi GN, Theriault RL, Porter L, Blayney D, Lipton A, Sinoff C, et al. Efficacy of pamidronate in reducing skeletal complications in patients with breast cancer and lytic bone metastases. Protocol 19 Aredia Breast Cancer Study Group. N Engl J Med. 1996:335:1785-91.

27. Smit EF, Fokkema E, Biesma B, Groen HJ, Snoek W, Postmus PE. A phase II study of paclitaxel in heavily pretreated patients with small-cell lung cancer. Br J Cancer. 1998;77:347-51.

28. Ciray l, Lindman $H$, Aström KG. Early response of breast cancer bone metastases to chemotherapy evaluated with MR imaging. Acta Radiol. 2001;42:198-206.

29. Tokito T, Shukuya T, Akamatsu H, Taira T, Ono A, Kenmotsu H, et al. Efficacy of bevacizumab-containing chemotherapy for non-squamous non-small cell lung cancer with bone metastases. Cancer Chemother Pharmacol. 2013;71:1493-8

30. Mouridsen HT, Ellemann K, Mattsson W, PalshofT, Daehnfeldt JL, Rose C. Therapeutic effect of tamoxifen versus tamoxifen combined with medroxyprogesterone acetate in advanced breast cancer in postmenopausal women. Cancer Treat Rep. 1979:63:171-5.

31. Lipton A, Harvey HA, Santen RJ, Boucher A, White D, Bernath A, et al. Randomized trial of aminoglutethimide versus tamoxifen in metastatic breast cancer. Cancer Res. 1982;42:3434s-s3436.

32. van Veelen H, Willemse PH, Tjabbes T, Schweitzer MJ, Sleijfer DT. Oral high-dose medroxyprogesterone acetate versus tamoxifen. A randomized crossover trial in postmenopausal patients with advanced breast cancer. Cancer. 1986;58:7-13.

33. Smith IE, Harris AL, Morgan M, Ford HT, Gazet JC, Harmer CL, et al. Tamoxifen versus aminoglutethimide in advanced breast carcinoma: a randomized cross-over trial. Br Med J (Clin Res Ed). 1981;283:1432-4.

34. Muss HB, Case LD, Atkins JN, Bearden JD 3rd, Gansauer L, Moore LA, et al. Tamoxifen versus high-dose oral medroxyprogesterone acetate as initial endocrine therapy for patients with metastatic breast cancer: a Piedmont Oncology Association study. J Clin Oncol. 1994;12:1630-8.

\section{Publisher's Note}

Springer Nature remains neutral with regard to jurisdictional claims in published maps and institutional affiliations. 